\title{
A PRÁTICA DOCENTE NA FORMAÇÃO DO PÓS-GRADUANDO EM QUÍMICA
}

\author{
Agnaldo Arroio* \\ Departamento de Metodologia do Ensino e Educação Comparada, Faculdade de Educação, Universidade de São Paulo, Av. da \\ Universidade, 308, 05508-040 São Paulo - SP, Brasil \\ Káthia Maria Honório \\ Escola de Artes, Ciências e Humanidades, Universidade de São Paulo, Av. Arlindo Bettio, 1000, 03828-000 São Paulo - SP, \\ Brasil \\ Paula Homem-de-Mello \\ Centro de Ciências Naturais e Humanas, Universidade Federal do ABC, Rua Santa Adélia, 166, 09210-170 Santo André - SP, \\ Brasil \\ Karen Cacilda Weber e Albérico B. F. da Silva \\ Departamento de Química e Física Molecular, Instituto de Química de São Carlos, Universidade de São Paulo, CP 780, 13560- \\ 790 São Carlos - SP, Brasil \\ Recebido em 5/9/07; aceito em 27/3/08; publicado na web em 26/9/08

\begin{abstract}
THE TEACHING PRACTICE IN THE CHEMISTRY GRADUATE STUDENT LEARNING. The present work describes how a group of chemistry graduate students have improved their teaching skills by teaching extension courses. It is suggested that future teachers have much to be gained by sharing the insights they have whilst teaching with their peers and students. This work explores the implications in teaching and learning and the relationship between teachers and students. This relationship requires mutual respect of ideas as well as continuous critical evaluation in both directions.
\end{abstract}

Keywords: teacher training; reflective teaching; chemistry learning.

\section{INTRODUÇÃO}

A formação de professores é hoje um dos assuntos mais discutidos em Educação, principalmente nos cursos de licenciatura. Muitas questões nos acompanham e são consideradas nas discussões: que profissional queremos formar? Quais os conhecimentos profissionais necessários à formação do professor? Que tipo de professor nossos cursos estão formando? Como formar um bom professor e um bom profissional? Dentre outras.

Esta discussão começa a emergir também nos cursos de PósGraduação, responsáveis pela formação de recursos humanos para a docência no ensino superior. ${ }^{1}$ A maior parte dos professores que atuam nas universidades não é oriunda de cursos de licenciatura, mas de cursos de bacharelado que, geralmente, não preparam para a docência e sim para a pesquisa. No entanto, serão estes professores que formarão os futuros profissionais. Porém, não basta reconhecer que a formação de professores é um dos fatores mais importantes para melhorar o processo de ensino-aprendizagem.

Idéias simples como "basta dominar o conteúdo" ou "basta aprender algumas técnicas e/ou metodologias de ensino" já foram superadas. ${ }^{2}$ Considerando o ensino como sendo um fenômeno social e complexo e não apenas metodológico, não basta oferecer aos alunos instrumentos metodológicos, com a ilusão de que isso basta para garantir uma boa prática docente. ${ }^{3}$ É importante que o docente reflita sobre os fins e valores que envolvem a docência para que possa se situar diante desta profissão e atuar plenamente em sua área.

O estágio de docência (Capes), ${ }^{4}$ disciplinas como "Prática de ensino" e "Preparação Pedagógica", o Programa de Aperfeiçoamento de Ensino (PAE-USP), etc. são algumas alternativas que vêm sendo desenvolvidas para que os pós-graduandos tenham em sua formação

\footnotetext{
*e-mail: agnaldoarroio@yahoo.com
}

a oportunidade de desenvolver e/ou aprimorar sua prática docente antes de sua atividade profissional.

A criação de novas formas de trabalho e as adaptações de prática docente estão relacionadas diretamente ao espírito crítico e reflexivo. Assim, é extremamente relevante para os alunos a oportunidade de vivenciar estas atividades relacionadas à docência em seu processo de formação, pois, através da reflexão sobre suas experiências, podem romper com o continuísmo tão arraigado em nossos cursos. A maior dificuldade para o recém-formado, no sentido de desenvolver atividades inovadoras, está relacionada ao medo de errar, sendo assim, é mais seguro simplesmente reproduzir os modelos tradicionais vivenciados (o que limita muito o fazer docente, baseado em um modelo comportamentalista).

Uma outra oportunidade para a formação dos futuros professores universitários consiste na colaboração em cursos de extensão. ${ }^{5}$ Estes se apresentam como um espaço em que o pós-graduando, em colaboração com um docente, pode vivenciar, experimentar e interpretar, reconstruindo sua prática docente. Assim pode-se desenvolver uma prática reflexiva, evidenciando que a prática docente é mutável e que suas reflexões, inovações e mudanças devem permear seu trabalho ao longo de sua vida. De acordo com Paulo Freire, ${ }^{6}$ é a partir do exercício de reflexão que o professor aprende a melhorar sua prática de sala de aula, ajudando assim seus alunos a aprenderem.

Os cursos de extensão universitária oferecem a oportunidade de realizar a integração do ensino, pesquisa e extensão, uma vez que podem ser relacionados a uma área de pesquisa específica e direcionados para uma difusão do conhecimento produzido na Universidade, quer seja para a comunidade interna ou externa. Por meio deste tipo de atividade, $\mathrm{o}$ aluno passa a vivenciar a prática docente, experiência muito mais rica e motivadora que apenas assistir aulas, discutir os problemas educacionais, fazer conjecturas de possíveis soluções, etc. A vivência engloba todas as atividades citadas anteriormente e 
proporciona uma reflexão sobre a experiência. O pós-graduando pode realizar a interação entre o conhecimento específico e o pedagógico, construindo a identidade profissional do futuro professor, rompendo com o modelo tradicional reproduzido em geral.

No presente trabalho foi analisada a experiência de um grupo de alunos do Programa de Pós-graduação em Físico-Química, do Instituto de Química de São Carlos, Universidade de São Paulo (IQSC/USP), na realização de cursos de extensão relacionados à química computacional, ${ }^{7}$ com o apoio da Comissão de Cultura e Extensão do IQSC/USP (CCEx/IQSC/USP). Ao final das atividades, foi realizada uma ampla discussão sobre as experiências provenientes dos cursos.

O grupo de pós-graduandos realizou, em conjunto com um docente responsável pelos projetos, dois cursos: "Farmacologia Quântica" e "Química Computacional". O primeiro tratava de um assunto bastante especifico, ou seja, uma aplicação da Química Quântica no planejamento de fármacos, enquanto o segundo procurava apresentar um amplo espectro das aplicações da Química Computacional. Esse fato se refletiu, evidentemente, na diferença de carga horária de cada curso; o primeiro foi realizado em $15 \mathrm{~h}$ e o segundo em $32 \mathrm{~h}$. Além das diferenças intrínsecas às ementas, os cursos apresentaram diferenças também com relação ao público alvo. O primeiro curso foi voltado exclusivamente a estudantes de graduação, enquanto o segundo contemplava tanto estudantes de graduação quanto de pós-graduação.

\section{METODOLOGIA}

Os cursos foram desenvolvidos e ministrados por três alunos do terceiro ano de Doutorado e por um aluno do segundo ano do Mestrado, todos do Programa de Pós-graduação em Físico-Química do IQSC/USP. Os projetos de pesquisa desenvolvidos pelos alunos são relacionados aos temas "estudos da relação estrutura-atividade de compostos biologicamente ativos", "planejamento de fármacos", "métodos de solvatação" e "simulação de espectros". Os alunos que ministraram os cursos já haviam cumprido os créditos exigidos pelo programa de pós-graduação no IQSC/USP, bem como o estágio no programa PAE.

Os alunos e o professor responsável elaboraram o projeto do curso "Farmacologia Quântica" e este foi submetido à Comissão de Cultura e Extensão (CCEx) do IQSC/USP para análise, sendo aprovado posteriormente.

O curso foi oferecido aos alunos do Bacharelado em Química do IQSC/USP, tendo prioridade os alunos que já haviam cursado a disciplina de Química Quântica, porém isso não era um pré-requisito. Dos 15 alunos que freqüentaram as aulas, 10 não haviam cursado a disciplina de Química Quântica e os outros 5 já haviam cursado a disciplina no semestre anterior ao curso. Porém, todos já haviam cursado disciplinas de Química Orgânica e Bioquímica, que eram relevantes para os estudos da relação estrutura-atividade.

Em função da infra-estrutura do laboratório de pesquisa do Grupo de Química Quântica do IQSC/USP, foram abertas 15 vagas, pois poderiam ser utilizados 5 microcomputadores para o desenvolvimento das aulas práticas. Verificou-se que este número de alunos propiciou maior discussão e interação, o que seria mais difícil em turmas maiores.

O curso foi desenvolvido no período da manhã durante uma semana, num total de $15 \mathrm{~h}$, sendo constituído de duas partes: parte teórica, com duração de 1:30 h, e parte prática, com duração de 1:30 h, onde os alunos formavam grupos de 3 alunos em cada microcomputador para conhecerem os programas e realizarem os exercícios propostos.

Cada pós-graduando foi responsável por ministrar um módulo teórico durante a semana e todos participavam das aulas práticas acompanhando os alunos. As aulas teóricas foram preparadas pelos ministrantes com recursos de PowerPoint e apresentados com o auxílio de um projetor data-show. Este recurso também foi utilizado na apresentação dos programas computacionais empregados em Química Quântica, onde foram utilizados o Hyperchem 7.0 e o Ampac 5.0.7

Os exercícios práticos eram propostos e discutidos no final de cada aula teórica e desenvolvidos posteriormente nas aulas práticas. Os resultados desses exercícios, obtidos pelos programas computacionais utilizados, eram entregues aos alunos no final da aula prática para que pudessem interpretar os resultados.

Além dos exercícios propostos, os alunos foram estimulados pelos ministrantes a propor um projeto, que consistia em buscar na literatura moléculas de interesse farmacológico e possíveis mecanismos de interação desses fármacos com um receptor. Juntamente com os ministrantes foram avaliadas as diversas propostas trazidas por cada grupo e, após verificadas as possibilidades de execução, foi escolhido um projeto por grupo. A etapa posterior consistiu no desenvolvimento, durante o curso, dos projetos escolhidos e estes foram apresentados na última aula por cada grupo em uma sessão onde os alunos ministrantes e todos os grupos podiam participar da argüição.

Tendo em vista o sucesso do primeiro curso, foi proposto à CCEx um segundo curso, "Química Computacional", aberto à participação de alunos de graduação e pós-graduação, com o mesmo número de vagas. Porém a duração deste curso foi estendida para $32 \mathrm{~h}$ ao longo do semestre letivo, com aulas teóricas, práticas e desenvolvimento de projetos nos moldes do primeiro curso, tendo em vista, porém, que os projetos já não se restringiam à pesquisa por fármacos.

Os alunos participantes e os cursos (que compreendem equipe de ministrantes, metodologia e conteúdo) foram avaliados de maneira contínua, por meio de discussões ao longo dos cursos. Os alunos participantes foram avaliados também pela apresentação dos resultados dos projetos e das experiências em um seminário. Os cursos foram também avaliados por um questionário aplicado aos alunos participantes, que além de pedir que avaliassem a equipe de ministrantes, a metodologia e o conteúdo sob diversos aspectos, propunha uma auto-avaliação. Os ministrantes do curso e o professor responsável se auto-avaliaram utilizando o formato de um workshop no qual ocorria uma discussão depois que cada participante apresentava sua experiência no processo.

Os dados coletados provêm de observações realizadas durante as interações entre todos os participantes que cursaram e que ministraram os cursos e os questionários de avaliação. Foi metodologicamente significativa a inclusão de todos os participantes como agentes históricos. Em outras palavras, acreditamos ser extremamente fundamental que cada participante veja a si próprio como parte do processo e tenha expectativa de que suas ações e avaliações, através de sua participação, possam se transformar em dados e conclusões que deverão realimentar as propostas iniciais.

\section{RESULTADOS E DISCUSSÃO}

Dentre os benefícios oferecidos por esta prática, destaca-se a participação dos alunos de pós-graduação em todas as etapas do curso, desde sua concepção até a avaliação, um importante diferencial quando comparado com as outras oportunidades presentes nos cursos de pós-graduação.

A discussão inicial referia-se ao tema que seria abordado no curso, quais os objetivos pretendidos, a duração e a legislação pertinente (uma vez que cada universidade possui suas próprias diretrizes para cursos de extensão universitária). Em seguida, tendo estabelecido o tema "Química Computacional" como norteador do projeto, foi necessário o planejamento do curso, preparando-se a ementa e o programa. Sendo esta uma das etapas mais complexas, pois a seleção dos conteúdos na preparação do programa do curso fica balizada 
pela duração e pela clientela a que se destina o curso, optou-se por preparar um programa aberto, ou seja, com conteúdos essenciais para o tema "Farmacologia Quântica". Porém, este tema era sujeito a modificações de acordo com a disponibilidade da bibliografia necessária na biblioteca e com o perfil dos alunos participantes, modificações estas discutidas no início da realização do curso. Em seguida foram selecionados os recursos didáticos que seriam utilizados, bem como alternativas caso estes não estivessem disponíveis no período de realização, assim como a disponibilidade do laboratório de informática e os programas computacionais necessários. Os resultados do primeiro curso foram tão positivos que levaram à realização do segundo, destinado aos alunos de graduação e pós-graduação.

Durante a realização dos cursos, cada ministrante foi responsável por um módulo, sendo que todos assistiam aos demais módulos com a finalidade de avaliar o desenvolvimento como um todo. Após cada módulo, os ministrantes se reuniram para discussão sobre a experiência docente de cada um. Esta etapa se mostrou muito proveitosa, pois permitiu a aquisição de conhecimento sobre os processos que ocorrem na sala de aula, bem como o domínio de estratégias de intervenções didáticas, o desenvolvimento de habilidades, estratégias de comunicação e compartilhamento de experiências.

O material didático elaborado para o primeiro curso foi revisado, aperfeiçoado e ampliado para o segundo, tendo em vista que o segundo curso envolvia um tema mais abrangente e que os alunos participantes já possuíam conhecimentos em relação à mecânica quântica. Assim, os conhecimentos foram aprofundados, visto que o primeiro curso (destinado exclusivamente a alunos de graduação) tratava apenas de um dos aspectos do tema mais geral "Química Computacional".

Após as primeiras aulas, alguns alunos apresentaram dificuldades em relação a alguns conteúdos iniciais sobre mecânica quântica, de acordo com seus relatos. Os ministrantes, depois de discussões sobre as dificuldades relatadas, retomaram esses conteúdos em aula posterior, favorecendo o processo ensino-aprendizagem dos alunos através da recuperação desses conteúdos, para que pudessem dar continuidade às aulas, uma vez que esses conteúdos seriam importantes nas aulas subsequientes, o que não seria possível por meio de uma avaliação apenas no final do curso. Assim, a avaliação foi realizada continuamente, aplicada ao longo de todo o processo, e não pontual, apenas no final do curso, o que permitiu que os cursos fossem modificados durante sua realização de acordo com o interesse e as dificuldades dos alunos participantes.

Desta forma, a avaliação foi mais eficiente, pois tanto os participantes quanto os ministrantes e o próprio curso foram continuamente avaliados. Portanto, foi possível averiguar as dificuldades encontradas pelos participantes, possibilitando o aprimoramento do curso com o intuito de saná-las. Este processo só foi possível devido a esta avaliação contínua, ao invés de uma única avaliação no final do curso sem retorno para os alunos. A avaliação realizada desta maneira se mostra mais bem sucedida, sendo os alunos participantes, o curso e os ministrantes objetos de avaliação.

No geral, os cursos foram avaliados como muito bons pelos alunos participantes. O aumento de carga horária do primeiro para o segundo curso foi sugerido pelos alunos em suas avaliações. Considerando esta sugestão dos alunos na avaliação, a carga horária foi aumentada de 15 para 32 h e o segundo curso foi desenvolvido de forma extensiva e não intensiva, como no primeiro, ou seja, no lugar de aulas diárias, o curso passou a ser ministrado em uma aula por semana com a duração de $3 \mathrm{~h}$.

Os principais comentários com relação à equipe ministrante eram: "pessoal com conhecimento do assunto", "preparado" e "didático". Estes comentários podem refletir a surpresa dos participantes ao verificarem que os alunos de pós-graduação conseguiram tornar um assunto como química teórica, muitas vezes considerado de difícil compreensão e de pouca aplicabilidade, em algo "atual" e com "aplicação tanto em pesquisa quanto na indústria".

Quando questionados sobre a diferença de um curso ministrado por um docente e o curso ministrado pelos alunos de pós-graduação, sob a supervisão de um docente, foi relatado que "muitas vezes os professores (docentes universitários) criam uma barreira", pois "às vezes o professor por trabalhar há muito tempo com determinado assunto e sabê-lo bastante torna sua compreensão mais difícil".

A interação entre o aluno de graduação (participante) e o de pósgraduação (ministrante) foi bastante relevante, fato extremamente importante, pois como os próprios alunos destacaram, "vocês estão mais próximos de nós". Esta é uma fala muito forte, que provoca uma análise crítica do profissional sobre o discurso e a prática docente na Universidade.

A relação professor-aluno é fundamental para um processo ensino-aprendizagem eficiente. Com essa abordagem, foi dada uma maior abertura aos alunos participantes para que pudessem intervir no decorrer do curso, tanto nas aulas teóricas como práticas. A interação entre os alunos de graduação e pós-graduação mostrou-se de fundamental importância, pois permitiu que o conteúdo fosse retomado e que o curso fosse adaptado de acordo com a realidade e as necessidades da turma.

Os alunos participantes de pós-graduação (no caso do segundo curso) ressaltaram que o fato do curso ser de responsabilidade do pós-graduando ministrante é muito importante na formação docente, "os cursos devem abranger diferentes níveis de formação como oportunidade para todos participarem" e "ajudam no desenvolvimento dos alunos", de acordo com os relatos dos alunos participantes. Desta forma, esses cursos colaboraram também para que os alunos se questionassem sobre as próprias experiências em docência e possam futuramente apresentar uma atitude mais crítica e participativa, enfim uma prática reflexiva.

A experiência em atividades deste tipo foi retratada pelos alunos ministrantes como extremamente valiosa para a formação docente, pois tiveram uma oportunidade ímpar, que nos tradicionais programas de estágio em docência citados anteriormente, em alguns casos, eles apenas acompanhariam o docente em suas aulas ou auxiliariam na preparação de material didático. Conforme relato de um aluno "eu me senti um professor", pode-se notar que o aluno estava construindo sua identidade de professor e não era mais um químico que dava aulas. Desta forma, os alunos ministrantes sentiram-se mais comprometidos com a docência, tanto por serem autores do projeto quanto por serem responsáveis pelo desenvolvimento e avaliação do curso de extensão "eu não estava dando aulas, eu estava participando da formação dos alunos". De acordo com este relato evidencia-se que o engajamento do aluno no processo ensino-aprendizagem foi muito importante, pois ele passa a perceber que a educação é um processo complexo. Esse desenvolvimento de habilidades de pesquisa do próprio ensino em aula propõe o desenvolvimento de inovações, mostrando que é possível ser um professor-pesquisador refletindo sobre sua prática docente.

A competência requerida a esta atividade é evidenciada pela sólida cultura geral necessária para possibilitar uma prática interdisciplinar e contextualizada. Um profissional competente, reflexivo e crítico dentro de sua área do saber, habilitado para exercer a docência e a pesquisa, pode ser forjado através destas atividades.

A dinâmica proporcionada por este tipo de atividade leva o aluno à permanente preocupação com sua formação dentro de uma atividade docente crítica, diretamente relacionada com o princípio do potencial do papel dos estudantes na transformação e melhoria da sociedade em que se encontram inseridos, revelado aqui, principalmente, pela difusão e democratização do conhecimento acadêmico.

Em relação aos alunos ministrantes, dois desses alunos começa- 
ram a cursar uma disciplina de Metodologia de Ensino de Química após a realização do primeiro curso e antes do segundo, buscando mais instrumentos e conhecimento para que pudessem aperfeiçoar sua formação docente.

Esses dois cursos incentivaram a realização de um próximo curso que terá como público alvo professores da rede pública de ensino, proporcionando aos alunos ministrantes não apenas uma experiência em docência, mas também a construção de uma relação entre a universidade e a comunidade externa a ela.

\section{CONCLUSÕES}

Os cursos de extensão apresentam-se como um espaço onde os alunos de pós-graduação podem vivenciar atividades relacionadas ao ensino, pesquisa e extensão, participando em todas as etapas desde a preparação e realização até a avaliação de um curso. Além disso, esses cursos são uma excelente oportunidade para discussão de teoria e prática de ensino, evidenciando a dimensão dinâmica do processo educativo.

Destacamos como aspectos essenciais para a formação desses futuros professores: concepção e planejamento do curso, preparando ementas e avaliações, bem como selecionando conteúdos, metodologias e bibliografias; contato com procedimentos burocráticos para implantação dos cursos, levando em conta a natureza do curso, carga horária, local e recursos necessários, de acordo com a legislação institucional; análise crítica das atividades, no que se refere, por exemplo, ao cumprimento dos objetivos, abordagens e contextualização dos conteúdos.

É necessário que o aluno tenha a oportunidade, em sua formação na pós-graduação, de romper com as concepções impostas e cultivadas por um sistema que enfatiza o modelo comportamentalista tradicional, tendo em vista principalmente seu papel na formação das gerações futuras. Através desta iniciativa para a formação docente, o aluno de pós-graduação pode desenvolver sua identidade de professor, algo essencial na docência no ensino superior. ${ }^{8}$

\section{AGRADECIMENTOS}

À Comissão de Cultura e Extensão Universitária do Instituto de Química de São Carlos (USP), CNPq, CAPES e FAPESP.

\section{REFERÊNCIAS}

1. Arroio, A.; Rodrigues Filho, U. P.; da Silva, A. B. F.; Quim. Nova 2006, 29, 1387.

2. Carvalho, A. M. P. de; Gil-Pérez, D.; Formação de Professores de Ciências, Cortez Editora: São Paulo, 1995.

3. Pimenta, S. G.; Anastasiou, C. G. L. das; Docência no ensino superior, Cortez Editora: São Paulo, 2002.

4. Feitosa, J. P. A.; Quim. Nova 2002, 25, 153.

5. Resolução CoCEX N ${ }^{0}$ 5072, de 16 de Setembro de 2003.

6. Freire, P.; Faundez, A.; Por Uma Pedagogia da Pergunta, Paz e Terra: Rio de Janeiro, 1985.

7. Arroio, A.; Honório, K. M.; Weber, K. C.; Homem-de-Mello, P.; Da Silva, A. B. F.; Quim. Nova 2005, 28, 360.

8. Arroio, A.; Teaching Training for Post-Graduate Students, Proceedings $8^{\text {th }}$ European Conference on Research in Chemical Education, Budapeste, Hungria, 2006 